\title{
Produtividade e qualidade de tomates Santa Cruz e Italiano em função do raleio de frutos
}

\author{
Fernando H Shirahige'; ${ }^{1}$ Arlete MT de Melo²; Luis Felipe V Purquerio²; Cássia Regina L Carvalho ${ }^{2}$; Paulo \\ César T de Melo ${ }^{1}$ \\ ${ }^{1}$ USP-ESALQ, Depto. Prod. Vegetal, C. Postal 09, 13418-900 Piracicaba-SP; ${ }^{2}$ IAC-APTA, Centro de Horticultura, C. Postal 28, $13012-$ \\ 970 Campinas-SP; fhshirah@usp.br; arlete@iac.sp.gov.br; felipe@iac.sp.gov.br; climonta@iac.sp.gov.br; pctmelo@esalq.usp.br
}

\begin{abstract}
RESUMO
O manejo do tomateiro cultivado em ambiente protegido, com ênfase no raleio de frutos, pode contribuir de forma significativa para a produção de frutos de qualidade superior, expressando assim o potencial de cada cultivar. Foi avaliado o efeito do raleio de frutos na produtividade e seus componentes e em alguns atributos de qualidade de frutos de genótipos de tomateiro dos segmentos Santa Cruz e Italiano de crescimento indeterminado, visando ao consumo in natura. Avaliaram-se 12 genótipos de tomate de mesa (seis híbridos experimentais e seis cultivares) e dois modos de condução (plantas conduzidas com e sem raleio de frutos). O experimento foi com parcelas subdivididas, distribuídas em blocos completos ao acaso com três repetições. As parcelas foram representadas pelos genótipos e as subparcelas pelos modos de condução. Avaliaram-se o número de frutos por planta, produtividade comercial de frutos, produtividade de frutos não-comercializáveis, massa média do fruto, comprimento e largura do fruto, $\mathrm{pH}$, teor de sólidos solúveis totais (SS), acidez titulável (AT), relação entre SS e AT, teor de ácido ascórbico e teor de licopeno. $\mathrm{O}$ raleio dos frutos proporcionou incremento da produtividade comercial, massa média, comprimento e largura do fruto para os híbridos THX-02 e THX-03, do segmento Santa Cruz, e THX-04, THX-05 e Netuno, do segmento Italiano e não mostrou vantagens para a produção e seus componentes para os demais genótipos e características avaliadas. Considerando o raleio de frutos, os genótipos Giuliana e Sahel obtiveram maior produtividade comercial e massa média do fruto. Sem o raleio de frutos, 'Netuno' alcançou maior número de frutos por planta, porém, o híbrido Sahel foi quem se destacou por apresentar maior produtividade comercial e massa média do fruto. O raleio não influenciou a qualidade organoléptica dos genótipos avaliados. 'Avalon' apresentou maior teor de ácido ascórbico que 'Netuno' e 'Sahel'. 'Débora Max', THX-01, THX-02 e THX-04 foram semelhantes entre si quanto ao teor de licopeno e superaram 'Giuliana', 'Sahel', THX-03 e THX-06.
\end{abstract}

Palavras-chave: Solanum lycopersicum, manejo cultural, características organolépticas, hortaliças, cultivo protegido, segmentação varietal.

\section{ABSTRACT \\ Yield and fruit quality of Santa Cruz and Italian tomatoes depending on fruit thinning}

The management of the tomato plant under greenhouse, with emphasis on fruit thinning, contributes significantly to the production of fruits of superior quality, expressing the potential of each cultivar. We determined the effect of fruit thinning on yield and its components in tomato hybrids of the Santa Cruz and Italian types of indeterminate growth, and we performed the qualitative characterization of the fruits, aiming in natura market. Twelve fresh-market tomato genotypes (six experimental hybrids and six commercial cultivars) and two training methods (with and without manual fruit thinning) were evaluated. A randomized complete block design was used in this trial, with splitplots and three replications. The plots were represented by genotypes and the subplots were constitued by training methods. Number of fruits per plant, yield of marketable and not marketable fruits, average fruit weight, fruit length and fruit width were measured. For quantitative characterization, $\mathrm{pH}$, soluble solids concentration (SS), tritratable acidity (AT), ascorbic acid content, SS and AT ratio and lycopene content were measured. The fruit thinning increased marketable yield, average weight, length and width for the Santa Cruz hybrids THX-02 and THX-03 and for THX-04, THX-05 and Netuno, classified as Italian type. The fruit thinning did not provide benefits for yield and its components for the other evaluated characteristics and genotypes. Giuliana and Sahel genotypes presented higher marketable yield and average fruit weight. Without fruit thinning, 'Netuno' reached the highest number of fruits per plant, but the hybrid Sahel showed higher marketable yield and average fruit weight. Thinning did not affect the organoleptic quality of the genotypes. 'Avalon' showed higher ascorbic acid content than 'Netuno' and 'Sahel', and 'Débora Max', 'THX-01', 'THX-02' and 'THX-04', which were similar to each other in the content of lycopene, overcame 'Giuliana', 'Sahel', 'THX-03', and 'THX-06'.

Keywords: Solanum lycopersicum L., cultural management, organoleptic characteristics, vegetable crops, protected crop, varietal segmentation.

(Recebido para publicação em 14 de julho de 2009; aceito em 10 de agosto de 2010) (Received on July 14, 2009; accepted on August 10, 2010)

\begin{abstract}
A cultura do tomate (Solanum lycopersicum L.) desempenha importante papel na economia nacional, sendo um dos principais produtos olerícolas. $\mathrm{O}$ Brasil se destaca entre os dez maiores países produtores, tendo alcançado, em 2008, um total de 3,77 milhões de
\end{abstract}

toneladas de tomate (FNP, 2009). A ampla utilização do tomate deve-se, principalmente, às suas qualidades organolépticas e ao seu valor como alimento funcional em vista das propriedades antioxidantes do licopeno, o pigmento carotenóide que dá a cor vermelha à grande maioria das cultivares existentes no mercado. Os principais pigmentos carotenóides encontrados são o licopeno e o beta-caroteno (Chitarra \& Chitarra, 1990).

A produção de tomate para consumo in natura no Brasil sofreu grandes 
transformações tecnológicas na última década, sendo que a introdução de híbridos do tipo longa vida foi, sem dúvida, uma das mais importantes. No entanto, a qualidade gustativa desses híbridos tem sido alvo de críticas, pois os mesmos genes que conferem a característica desejável "longa vida" causam também alterações indesejáveis no sabor, aroma, textura e teor de licopeno (Melo, 2003). Para atenuar o impacto negativo junto ao consumidor devido à expansão dos híbridos Salada longa vida, as empresas do setor sementeiro vêm investindo em maior diversificação varietal. $\mathrm{O}$ maior interesse das empresas é disponibilizar para o consumidor tipos de tomate com melhor qualidade gustativa e diferenciados em termos de tamanho, cor, formato, firmeza e textura (Dorais et al., 2001). Dentro dessa estratégia, os tomates do tipo Italiano ou Saladete têm mostrado tendência de expansão de cultivo nos últimos anos. Em geral, os frutos das cultivares híbridas desse padrão disponíveis no mercado têm excelente qualidade gustativa e versatilidade de uso culinário, podendo ser consumidos em saladas, na confecção de molhos caseiros e na forma de tomate seco (Machado et al., 2007). De outro lado, as versões híbridas da cultivar Santa Clara têm atraído também a atenção de uma parcela do setor produtivo por apresentarem frutos de maior durabilidade pós-colheita sem que possuam quaisquer dos genes que retardam o processo de maturação e alto potencial produtivo. Ademais, as vantagens desses híbridos, em comparação aos longa vida convencionais, é que seus frutos têm características organolépticas superiores, além de serem uniformes e exibirem coloração vermelha mais intensa. Com efeito, essa diversificação é positiva e favorece os consumidores que passaram a ter uma gama cada vez mais diversificada de tomates à sua disposição nos pontos de venda.

É importante destacar que na cultura do tomateiro, incrementos na produtividade podem ser logrados com a adoção de técnicas de manejo cultural diferenciadas. Segundo Tanaka \& Fujita (1974) o tomateiro pode ser dividido em unidades fonte-dreno. As folhas são fontes de fotoassimilados e os frutos os principais drenos. Os fotoassimilados de uma folha podem ser translocados para qualquer fruto, dependendo das condições da planta. Como os frutos são drenos metabólicos fortes, os fotoassimilados são translocados preferencialmente a estes órgãos (Peluzio et al., 1999). A relação fonte-dreno pode exercer influência nas variações da produção por planta, bem como no tamanho e massa individual dos frutos (Peluzio et al., 1999). Portanto, o raleio ou desbaste de frutos é uma técnica cultural que quando adotada pelos produtores pode alterar a relação fonte-dreno, propiciando aumento da produtividade, no tamanho e peso médio dos frutos, bem como na qualidade dos mesmos (Alvarenga, 2004).

O teor de sólidos solúveis é uma das principais características dos frutos no que diz respeito ao sabor, visto que é nesta fração que se encontram os açúcares e os ácidos. Este teor é também indicador da qualidade dos frutos e dos seus subprodutos. Quanto maior for o teor de sólidos solúveis, maior será o rendimento industrial. De acordo com Dorais et al. (2001) e Caliman (2003), a maior disponibilidade de fotoassimilados aos frutos pode ocasionar o aumento do tamanho bem como propiciar uma melhoria de sabor.

Existem poucas informações sobre a produção de tomates do segmento Santa Cruz e Italiano sob o efeito do raleio de frutos em ambiente protegido. Dessa forma, o objetivo do presente trabalho foi avaliar o efeito do raleio de frutos na produtividade e qualidade de tomates de cultivares de crescimento indeterminado dos segmentos Santa Cruz e Italiano, em ambiente protegido.

\section{MATERIAL E MÉTODOS}

Um experimento foi conduzido de 26 de fevereiro a 11 de setembro de 2008, em condições de ambiente protegido (estufa agrícola), no Centro de Horticultura do Instituto Agronômico (IAC), em Campinas-SP, (22054'20"S, 47005'34"W, $674 \mathrm{~m}$ de altitude). O delineamento experimental foi blocos completos ao acaso, com parcelas subdivididas, com 12 tratamentos e três repetições. As parcelas foram representadas pelas cultivares e as subparcelas pelo raleio, avaliando-se plantas com e sem raleio de frutos. A parcela foi composta por dois canteiros de fileiras simples, com oito plantas totais. Como bordaduras, foram utilizadas três plantas em cada extremidade dos canteiros. Foram avaliados seis híbridos experimentais (três do grupo Santa Cruz denominados THX01, THX-02 e THX-03 e três do grupo Italiano denominados THX-04, THX-05 e THX-06) oriundos do programa de melhoramento genético do IAC, Campinas. Como testemunhas, usaram-se seis cultivares comerciais, sendo três do grupo Italiano: Giuliana (Sakata), Netuno (Eagle) e Sahel (Syngenta), e três do grupo Santa Cruz: Avalon (Hortivale), Débora Max (Sakata) e Maravilha.

A calagem e as adubações de plantio e cobertura foram realizadas com base em análise, seguindo-se a recomendação de adubação e calagem para o Estado de São Paulo (Trani \& Raij, 1996). Produziram-se as mudas em bandejas de poliestireno expandido com 128 células, preenchidos com o substrato comercial Plantmax $\AA$, que foram transplantadas para canteiros de $0,6 \times 30 \mathrm{~m}$ quando atingiram o estádio de quatro a cinco folhas definitivas, aos 40 dias após a semeadura. A condução foi feita com haste única, sendo as plantas distribuídas em canteiros distanciados de $0,4 \mathrm{~m}$ entre si, com espaçamento de $0,55 \mathrm{~m}$ entre plantas na linha. Tutorou-se cada planta individualmente com fitilho, eliminando-se todas as brotações das axilas das folhas. As hastes das plantas foram podadas após a emissão do $8^{\circ}$ racemo. Após o pegamento dos frutos, foi feito o raleio dos mesmos nas subparcelas determinadas, deixando-se seis frutos por racemo.

Aos 110 dias após o transplante (DAT), em 15/07/2008, iniciou-se a colheita dos frutos de cada tratamento no estádio de maturação totalmente vermelho e ainda firme, prolongandose por nove semanas, realizando-se uma colheita por semana. Avaliou-se: a) número de frutos por planta $(\mathrm{FP})$; b) produtividade comercial de frutos (PC), obtida pela massa total de frutos com diâmetro transversal maior que $33 \mathrm{~mm}$ e sem defeitos (sintomas de doenças, pragas, distúrbios fisiológicos e/ou da- 
nos físicos), com resultado expresso em toneladas por hectare; c) produtividade de frutos não-comercializáveis (PR), obtida pela massa total de frutos com diâmetro transversal menor que $33 \mathrm{~mm}$ e de frutos com defeitos, com resultado expresso em toneladas por hectare; d) massa média do fruto (MM), relação entre a produtividade comercial de frutos (massa) e o número de frutos comerciais, com resultado expresso em gramas por fruto; e) comprimento (CM) e f) largura do fruto (LR), avaliados com uso de um paquímetro digital (Mitutoyo 150 $\mathrm{mm}$ ) em 60 frutos comerciais coletados ao acaso de plantas de cada subparcela, a partir da segunda colheita, avaliando 10 frutos por colheita e expressando os resultados em centímetro.

As análises das características qualitativas foram realizadas em laboratório do IAC, em Campinas. Aos 130 dias após o transplante, colheram-se 12 frutos de cada subparcela no estádio de maturação completa, com frutos vermelhos e firmes, e determinaram-se as características físico-químicas: a) teor de sólidos solúveis (SS), determinado pela leitura direta em refratômetro digital "Atago modelo Palete 101", utilizando-se da polpa homogeneizada em triturador doméstico tipo 'mixer', sendo os resultados expressos em ${ }^{\circ}$ Brix; b) acidez titulável (AT), determinada de acordo com o método descrito por Carvalho et al. (1990), expressandose os resultados em porcentagem de ácido cítrico da polpa; c) teor de ácido ascórbico (AA), determinado por titulometria, de acordo com o método descrito por Carvalho et al. (1990), sendo os resultados expressos em $\mathrm{mg}$ de ácido ascórbico por $100 \mathrm{~g}$ de polpa; d) $\mathrm{pH}$, aferido pela leitura direta em peagâmetro marca Tecnal; e) sabor (flavor), obtido pela relação entre os teores de sólidos solúveis e acidez titulável (SS/AT); f) licopeno (LI), determinado por análise espectrofotométrica, de acordo com o método descrito por Rodrigues-Amaya (2001), sendo os resultados expressos em microgramas de licopeno em 100 gramas de polpa.

Os valores dos componentes da produção bem como das características qualitativas dos frutos foram submetidos à análise de variância. Utilizou-se o programa estatístico SISVAR, versão 4.3. As médias foram comparadas pelo teste de Tukey a 5\%.

\section{RESULTADOS E DISCUSSÃO}

Para os componentes de produção avaliados, houve efeito significativo da interação entre o manejo (raleio de frutos e não raleado) e cultivares. Os híbridos THX-02, THX-03, Netuno, Sahel, THX-04 e THX-05 apresentaram maior FP nas plantas sem raleio de frutos (Tabela 1), com valores que variaram de 57,3 ('Sahel') a 76,0 frutos planta ${ }^{-1}$ ('Netuno'). Os demais genótipos, não foram afetados pelo raleio. Uma provável explicação para tal ocorrência pode estar relacionada à seleção de combinações híbridas de tomate de mesa com tendência de fixar poucos frutos por racemo ( 5 a 6), visando obter aumento da massa média do fruto. Segundo Nagai (1990), os programas privados de melhoramento genético dedicaram esforços nesse sentido uma vez que frutos com massa média entre 200 e 250 gramas recebiam maior cotação de preços na comercialização. Considerando as plantas sem raleio de fruto, o genótipo Netuno obteve maior número de frutos por planta $(76,0$ frutos planta-1 ${ }^{-1}$. Machado et al. (2007) reportaram resultados de um ensaio com tomate do segmento Italiano ou Saladete realizado sob diferentes densidades de plantio e sistemas de poda, em que obtiveram média de 57,2 frutos planta ${ }^{-1}$ deixando oito cachos por planta, porém, não foi analisado o efeito do raleio. Deve ser ressaltado que são raros os trabalhos

Tabela 1. Número de frutos por planta (FP), produtividade comercial (PC) e produtividade de frutos não-comercializáveis (PR) das cultivares de tomate dos segmentos Santa Cruz e Italiano, com e sem raleio de frutos [number of fruits per plant (FP), marketable yield (PC) and not marketable fruit yield (PR) of Santa Cruz and Italian tomato types, according to fruit thinning and non-thinning]. Campinas, IAC, 2008.

\begin{tabular}{|c|c|c|c|c|c|c|}
\hline \multirow{2}{*}{ Cultivar* } & \multicolumn{2}{|c|}{ FP (frutos planta ${ }^{-1}$ ) } & \multicolumn{2}{|c|}{ PC (t ha-1) } & \multicolumn{2}{|c|}{$\operatorname{PR}\left(\mathrm{t} \mathrm{ha}^{-1}\right)$} \\
\hline & Raleado & Não raleado & Raleado & Não raleado & Raleado & Não raleado \\
\hline Híb. Avalon & $47,0 \mathrm{Aa}^{1}$ & $47,7 \mathrm{Ea}$ & $104,3 \mathrm{Ca}$ & $99,7 \mathrm{CDEa}$ & $10,4 \mathrm{ABa}$ & $11,2 \mathrm{Da}$ \\
\hline Híb. Débora Max & $47,7 \mathrm{Aa}$ & $48,7 \mathrm{Ea}$ & $100,1 \mathrm{CDa}$ & 99,6 CDEa & $13,1 \mathrm{Aa}$ & $12,1 \mathrm{Da}$ \\
\hline PA Maravilha & $47,5 \mathrm{Aa}$ & $49,0 \mathrm{Ea}$ & $89,2 \mathrm{Ea}$ & $90,2 \mathrm{EFGa}$ & $13,6 \mathrm{Aa}$ & $12,0 \mathrm{Da}$ \\
\hline Híb. THX-01 & $47,8 \mathrm{Aa}$ & $49,3 \mathrm{Ea}$ & $102,1 \mathrm{CDa}$ & $101,3 \mathrm{Ca}$ & $12,9 \mathrm{ABa}$ & $14,2 \mathrm{Da}$ \\
\hline Híb. THX-02 & $48,0 \mathrm{Ab}$ & $63,7 \mathrm{Ca}$ & $94,3 \mathrm{DEa}$ & $80,7 \mathrm{GHb}$ & $6,8 \mathrm{Bb}$ & $28,8 \mathrm{BCa}$ \\
\hline Híb. THX-03 & $48,0 \mathrm{Ab}$ & $65,2 \mathrm{BCa}$ & $88,8 \mathrm{Ea}$ & $77,5 \mathrm{Hb}$ & $11,3 \mathrm{ABb}$ & $27,9 \mathrm{Ca}$ \\
\hline Híb. Netuno & $48,0 \mathrm{Ab}$ & $76,0 \mathrm{Aa}$ & $118,3 \mathrm{Ba}$ & $100,6 \mathrm{CDb}$ & $7,8 \mathrm{ABb}$ & $36,0 \mathrm{Aa}$ \\
\hline Híb. Giuliana & $47,5 \mathrm{Aa}$ & $49,3 \mathrm{Ea}$ & $128,8 \mathrm{Aa}$ & $126,1 \mathrm{Ba}$ & $9,8 \mathrm{ABa}$ & $11,4 \mathrm{Da}$ \\
\hline Híb. Sahel & $48,0 \mathrm{Ab}$ & $57,3 \mathrm{Da}$ & $131,5 \mathrm{Ab}$ & 140,5 Aa & $9,8 \mathrm{ABa}$ & $12,7 \mathrm{Da}$ \\
\hline Híb. THX-04 & $47,8 \mathrm{Ab}$ & $63,8 \mathrm{BCa}$ & $117,1 \mathrm{Ba}$ & 98,5 CDEb & $8,9 \mathrm{ABb}$ & $34,3 \mathrm{ABa}$ \\
\hline Híb. THX-05 & $48,0 \mathrm{Ab}$ & $66,7 \mathrm{Ba}$ & $103,3 \mathrm{CDa}$ & $87,6 \mathrm{FGb}$ & $10,2 \mathrm{ABb}$ & $37,3 \mathrm{Aa}$ \\
\hline Híb. THX-06 & 47,5 Aa & $48,8 \mathrm{Ea}$ & $93,8 \mathrm{DEa}$ & $91,3 \mathrm{DEFa}$ & $10,2 \mathrm{ABa}$ & $12,5 \mathrm{Da}$ \\
\hline CV parc. $(\%)$ & \multicolumn{2}{|r|}{1,68} & \multicolumn{2}{|c|}{2,91} & \multicolumn{2}{|c|}{12,77} \\
\hline CV subparc. $(\%)$ & \multicolumn{2}{|c|}{2,30} & \multicolumn{2}{|c|}{3,65} & \multicolumn{2}{|c|}{15,43} \\
\hline
\end{tabular}

*Híb.= híbrido; $\mathrm{PA}=$ polinização aberta; ${ }^{1}$ Médias seguidas pelas mesmas letras maiúsculas na coluna e minúsculas na linha, não diferem entre si pelo teste de Tukey a $5 \%$. 
Tabela 2. Massa média (MM), comprimento (CM) e largura (LR) do fruto das cultivares de tomate dos segmentos Santa Cruz e Italiano, com e sem raleio de frutos [average fruit weight (MM), fruit length (CM), fruit width (LR) of Santa Cruz and Italian tomato types, according to fruit thinning and non-thinning]. Campinas, IAC, 2008.

\begin{tabular}{|c|c|c|c|c|c|c|}
\hline \multirow{2}{*}{ Cultivar* } & \multicolumn{2}{|c|}{ MM (g fruto ${ }^{-1}$ ) } & \multicolumn{2}{|c|}{$\mathrm{CM}(\mathrm{cm})$} & \multicolumn{2}{|c|}{ LR (cm) } \\
\hline & Raleado & Não raleado & Raleado & Não raleado & Raleado & Não raleado \\
\hline Híb. Avalon & $150,3 \mathrm{BCDa}^{1}$ & $147,7 \mathrm{Ba}$ & $6,7 \mathrm{EFa}$ & $6,4 \mathrm{DEa}$ & $6,7 \mathrm{Aa}$ & $6,4 \mathrm{Aa}$ \\
\hline Híb. Débora Max & $143,8 \mathrm{CDEa}$ & $141,1 \mathrm{BCa}$ & $6,2 \mathrm{Fa}$ & $6,4 \mathrm{DEa}$ & 5,8 CDEFa & $6,1 \mathrm{ABCa}$ \\
\hline PA Maravilha & 131,4 FGHa & $129,5 \mathrm{DEFa}$ & $6,6 \mathrm{EFa}$ & $6,3 \mathrm{Ea}$ & $6,4 \mathrm{ABCa}$ & $6,0 \mathrm{ABCa}$ \\
\hline Híb. THX-01 & $142,1 \mathrm{CDEFa}$ & $141,7 \mathrm{BCa}$ & $6,8 \mathrm{EFa}$ & 6,7 CDEa & 6,2 ABCDa & $6,0 \mathrm{ABCa}$ \\
\hline Híb. THX-02 & 128,1 GHa & $118,5 \mathrm{Fb}$ & $6,9 \mathrm{DEFa}$ & $6,3 \mathrm{~Eb}$ & 6,1 ABCDEa & $5,6 \mathrm{BCDb}$ \\
\hline Híb. THX-03 & $122,7 \mathrm{Ha}$ & $106,2 \mathrm{~Gb}$ & 7,9 $\mathrm{BCa}$ & 6,1 Eb & $6,6 \mathrm{ABa}$ & $5,6 \mathrm{CDb}$ \\
\hline Híb. Netuno & $156,8 \mathrm{Ba}$ & $142,0 \mathrm{BCb}$ & $8,3 \mathrm{BCa}$ & 7,7 Bb & $5,3 \mathrm{FGa}$ & 4,9 Eb \\
\hline Híb. Giuliana & $169,4 \mathrm{Aa}$ & $169,1 \mathrm{Aa}$ & 9,9 Aa & 9,6 Aa & 6,0 BCDEFa & $5,8 \mathrm{ABCa}$ \\
\hline Híb. Sahel & $172,9 \mathrm{Aa}$ & $166,8 \mathrm{Aa}$ & 7,8 BCDa & 7,6 BCa & $6,4 \mathrm{ABCa}$ & $6,3 \mathrm{Aba}$ \\
\hline Híb. THX-04 & $153,3 \mathrm{BCa}$ & $138,5 \mathrm{CDb}$ & $8,0 \mathrm{BCa}$ & $7,2 \mathrm{BCDb}$ & $5,6 \mathrm{DEFa}$ & $5,0 \mathrm{DEb}$ \\
\hline Híb. THX-05 & $139,8 \mathrm{DEFa}$ & $126,3 \mathrm{EFb}$ & $8,7 \mathrm{Ba}$ & 7,7 Bb & 5,4 EFGa & 4,9 Eb \\
\hline Híb. THX-06 & $134,6 \mathrm{EFGa}$ & $133,3 \mathrm{CDEa}$ & 7,5 CDEa & 7,4 $\mathrm{BCa}$ & $4,9 \mathrm{Ga}$ & $5,1 \mathrm{DEa}$ \\
\hline CV parc. $(\%)$ & \multicolumn{2}{|c|}{2,19} & \multicolumn{2}{|r|}{4,36} & \multicolumn{2}{|c|}{4,61} \\
\hline CV subparc. $(\%)$ & \multicolumn{2}{|c|}{3,27} & \multicolumn{2}{|r|}{4,09} & \multicolumn{2}{|c|}{3,76} \\
\hline
\end{tabular}

existentes na literatura envolvendo esses segmentos de tomate mostrando o efeito do raleio no número de frutos por planta bem como no aumento da massa média de fruto.

Para produtividade comercial de frutos (PC), dentro do grupo Santa Cruz, os híbridos experimentais THX-02 e THX-03 mostraram PC superiores em $16,8 \%$ e $14,6 \%$, respectivamente, nas plantas que foram raleadas em comparação àquelas não raleadas (Tabela 1). Para o segmento Italiano, o raleio de frutos influenciou o desempenho de 'Netuno', THX-04 e THX-05. Esses híbridos, quando raleados, alcançaram produções superiores em 17,6\%, 18,9\% e $17,9 \%$, respectivamente, em comparação ao desempenho deles sem raleio. Somente o híbrido Sahel obteve maior PC, em 6,8\% (140,5 $\left.\mathrm{t} \mathrm{ha}^{-1}\right)$, nas plantas não raleadas quando comparadas às raleadas $\left(131,5 \mathrm{t} \mathrm{ha}^{-1}\right)$. Considerando o raleio de fruto, os genótipos Giuliana e Sahel alcançaram maior PC. Dentro das plantas sem o raleio de fruto, o híbrido Sahel foi quem obteve maior PC. Machado et al. (2007) encontraram média da produtividade comercial de 111,3 t $\mathrm{ha}^{-1}$ em plantas do segmento Italiano ou Saladete com espaçamento entre plantas de $0,5 \mathrm{~m}$, espaçamento entre linhas de $0,8 \mathrm{~m}$ e com oito cachos por planta. Wamser et al. (2007), avaliando a produção de tomate Débora e Nemo Netta, em função do espaçamento entre plantas e do número de cachos por haste no tutoramento vertical com fitilho, relataram média da produtividade comercial de $94,5 \mathrm{t} \mathrm{ha}^{-1}$. Ambos os autores não avaliaram o efeito do raleio.

Somente o híbrido Sahel apresentou maior PC e FP, em $6,8 \%$ e $19,4 \%$, respectivamente, nas plantas não raleadas quando comparadas às raleadas, $\mathrm{e}$ foi estatisticamente semelhante na PR, MM, CM e LR nos dois sistemas de manejo das plantas (Tabelas 1 e 2). Sendo assim, o efeito do raleio de frutos não mostrou vantagens para produção nesse genótipo. Esse híbrido é reconhecidamente de alto potencial produtivo e tem a tendência de exibir elevado pegamento de frutos por racemo (Shirahige et al., 2009).

Para produtividade de frutos não-comercializáveis (PR) do tipo Santa Cruz, os híbridos experimentais THX-02 e THX-03 apresentaram reduções nas produções de frutos não-comercializáveis em $76,4 \%$ e $59,5 \%$, respectivamente, nas plantas raleadas quando comparadas às não raleadas (Tabela 1 ). Para o segmento Italiano, o raleio de fruto influenciou positivamente o desempe- nho de 'Netuno', THX-04 e THX-05, os quais produziram, respectivamente, $78,3 \%, 74,0 \%$ e $72,6 \%$ menos frutos não comercializáveis nas plantas submetidas ao raleio quando comparadas às não raleadas (Tabela 1). Isso se deve, provavelmente, à redução do número de frutos nas plantas submetidas ao raleio que, por consequência, contribuiu para o aumento da massa média do fruto e diminuição de frutos não-comercializáveis. Apesar de 'Netuno' e THX-05 terem alcançado maior média de FP em plantas não submetidas ao raleio de fruto, foram os que atingiram maior PR (36,0 e 37,3 $\mathrm{t} \mathrm{ha}^{-1}$, respectivamente).

Para massa média do fruto (MM) o efeito do raleio variou conforme o híbrido de ambos os segmentos varietais (Tabela 2). No grupo Santa Cruz, os híbridos experimentais THX-02 e THX-03 mostraram MM superiores em $8,1 \%$ e $15,5 \%$, respectivamente, nas plantas que receberam o raleio de fruto quando comparados às sem raleio. Por sua vez, para o segmento Italiano, o efeito do raleio de fruto influenciou o desempenho dos híbridos Netuno, THX-04 e THX-05, que alcançaram produções superiores em 10,4\%; 10,7\% e $10,7 \%$, respectivamente, nas plantas que foram raleadas quando compara- 
Tabela 3. Valores de pH, teor de sólidos solúveis (SS), acidez titulável (AT), relação entre SS e AT (SS/AT), teor de ácido ascórbico (AA) e teor de licopeno (LI), das cultivares de tomate dos segmentos Santa Cruz e Italiano, com e sem raleio de frutos [values of $\mathrm{pH}$, soluble solid content (SS), titratable acidity (AT), SS and AT ratio (SS/AT), ascorbic acid (AA) and lycopene (LI) of Santa Cruz and Italian tomato types, according to fruit thinning and non-thinning]. Campinas, IAC, 2008.

\begin{tabular}{|c|c|c|c|c|c|c|}
\hline Tratamento & pH & SS (\%) & AT $(\%)$ & SS/AT & $\begin{array}{c}\mathrm{AA} \\
\left(\mathrm{mg} \mathrm{100g}^{-1}\right)\end{array}$ & $\begin{array}{c}\text { LI } \\
\left(\mu \mathrm{g} \mathbf{1 0 0 g}^{-1}\right)\end{array}$ \\
\hline Raleado & $4,16 \mathrm{a}^{1}$ & $4,56 \mathrm{a}$ & $0,34 \mathrm{a}$ & $13,74 \mathrm{a}$ & $21,22 \mathrm{a}$ & $4.544,96 \mathrm{a}$ \\
\hline Não raleado & $4,16 \mathrm{a}$ & $4,64 \mathrm{a}$ & $0,35 \mathrm{a}$ & $13,37 \mathrm{a}$ & $21,84 \mathrm{a}$ & $4.330,70 \mathrm{a}$ \\
\hline CV (\%) & 1,34 & 6,19 & 13,42 & 11,28 & 13,39 & 20,77 \\
\hline
\end{tabular}

dos às sem raleio. Esses resultados se devem, ao que tudo indica, à alteração da relação fonte/dreno das plantas que sofreram o raleio, aumentando o teor de assimilados disponíveis por fruto nos cachos que foram submetidos ao raleio. Tais resultados foram também relatados por Leal et al. (2003) e Shirahige et al. (2009), que obtiveram médias do MM estatisticamente superiores em plantas cultivadas sob raleio. Tanto nas plantas submetidas ao raleio e sem raleio de fruto, os genótipos Giuliana e Sahel alcançaram maior massa média do fruto.

A influência do raleio no comprimento do fruto (CM) variou conforme o híbrido dentro de cada grupo varietal estudado (Tabela 2). Para o grupo Santa Cruz, os híbridos experimentais THX02 e THX-03 mostraram CM superiores em $9,5 \%$ e $29,5 \%$, respectivamente, nas plantas submetidas ao raleio, quando comparadas às sem raleio. Tanto nas plantas submetidas ao raleio e sem raleio de fruto, o genótipo Giuliana obteve maior comprimento médio do fruto. Os resultados confirmam o padrão típico de fruto de cada grupo varietal estudado em que o comprimento é o principal diferencial. Alvarenga (2004) considerou que as cultivares dos grupos Italiano ou Saladete têm comprimento de fruto que varia de 7 a $10 \mathrm{~cm}$. Por sua vez, as cultivares do grupo Santa Cruz produzem frutos mais curtos com comprimento variando de 6 a $8 \mathrm{~cm}$. No presente estudo, para o segmento Italiano, o efeito do raleio de fruto exerceu influência sobre o CM dos híbridos Netuno, THX-04 e THX-05, contribuindo para a produção de frutos maiores em 7,8\%, 11,1\% e $13,0 \%$, respectivamente, nas plantas que foram raleadas quando comparadas às cultivadas sem raleio de fruto. Melo et al. (2007), avaliando cruzamentos dialélicos entre genótipos de tomateiro de mesa, relataram médias de CM entre 6,0 e $7,6 \mathrm{~cm}$.

Com relação à largura do fruto (LR), os híbridos avaliados foram influenciados da mesma maneira que o comprimento do fruto (CM), sendo que o efeito do raleio dependeu de cada genótipo. No grupo Santa Cruz, os híbridos experimentais THX-02 e THX-03 mostraram largura de fruto superior em 8,9\% e $17,9 \%$, respectivamente, nas plantas cultivadas sob raleio quando comparadas às sem raleio de fruto. Os resultados confirmam a descrição encontrada nos catálogos das empresas de sementes de que o padrão de largura dos frutos das cultivares do tipo Santa Cruz é mais largo que o dos híbridos do segmento Italiano. No presente trabalho, no tocante ao segmento Italiano, o efeito do raleio de fruto influenciou a LR dos híbridos Netuno, THX-04 e THX-05 propiciando frutos maiores em 8,2\%, 12,0\% e 10,2\%, respectivamente, nas plantas que foram raleadas em comparação às não raleadas. Isso pode ser atribuído ao menor número de frutos por planta e maior massa média dos frutos nas plantas raleadas (Tabelas 1 e 2 , respectivamente), resultando em maior crescimento dos frutos devido à menor competição por fotoassimilados

Tabela 4. Valores de pH, teor de sólidos solúveis (SS), acidez titulável (AT), relação entre SS e AT (SS/AT), teor de ácido ascórbico (AA) e teor de licopeno (LI) em tomates das cultivares dos segmentos Santa Cruz (SC) e Italiano (IT) [values of pH, soluble solid (SS), titratable acidity (AT), SS and AT ratio (SS/AT), ascorbic acid (AA) and lycopene (LI) of tomato fruits of cultivars of Santa Cruz (SC) and Italian (IT) types]. Campinas, IAC, 2008.

\begin{tabular}{lcllllcl}
\hline \multicolumn{1}{c}{ Cultivar* } & Tipo & $\mathbf{p H}$ & SS (\%) & AT (\%) & SS/AT & AA $\left(\mathbf{m g} \mathbf{~ 1 0 0 g}^{-1}\right)$ & $\left.\mathbf{L I}^{(\boldsymbol{\mu g} \mathbf{~ 1 0 0 g}} \mathbf{g}^{-1}\right)$ \\
\hline Híb. Avalon & SC & $4,11 \mathrm{abc}$ & $5,0 \mathrm{a}$ & $0,39 \mathrm{ab}$ & $13,1 \mathrm{ab}$ & $25,0 \mathrm{a}$ & $5.252,7 \mathrm{ab}$ \\
Híb. Débora Max & SC & $4,17 \mathrm{abc}$ & $5,0 \mathrm{a}$ & $0,38 \mathrm{abc}$ & $13,3 \mathrm{ab}$ & $22,4 \mathrm{ab}$ & $5.707,7 \mathrm{a}$ \\
PA Maravilha & SC & $4,13 \mathrm{abc}$ & $4,8 \mathrm{ab}$ & $0,37 \mathrm{abc}$ & $12,9 \mathrm{ab}$ & $22,0 \mathrm{abc}$ & $4.649,8 \mathrm{abc}$ \\
Híb. THX-01 & SC & $4,19 \mathrm{abc}$ & $4,8 \mathrm{ab}$ & $0,34 \mathrm{abc}$ & $14,0 \mathrm{ab}$ & $23,4 \mathrm{ab}$ & $5.538,6 \mathrm{a}$ \\
Híb. THX-02 & SC & $4,09 \mathrm{bc}$ & $4,8 \mathrm{ab}$ & $0,41 \mathrm{a}$ & $12,0 \mathrm{ab}$ & $22,4 \mathrm{ab}$ & $5.358,1 \mathrm{a}$ \\
Híb. THX-03 & SC & $4,07 \mathrm{c}$ & $3,8 \mathrm{~d}$ & $0,37 \mathrm{abc}$ & $10,3 \mathrm{~b}$ & $23,7 \mathrm{ab}$ & $3.354,8 \mathrm{~cd}$ \\
Híb. Netuno & IT & $4,21 \mathrm{ab}$ & $4,4 \mathrm{bcd}$ & $0,28 \mathrm{c}$ & $15,7 \mathrm{a}$ & $17,7 \mathrm{bc}$ & $4.049,0 \mathrm{abc}$ \\
Híb. Giuliana & IT & $4,19 \mathrm{abc}$ & $4,1 \mathrm{~cd}$ & $0,29 \mathrm{bc}$ & $14,2 \mathrm{ab}$ & $19,5 \mathrm{abc}$ & $2.194,5 \mathrm{~d}$ \\
Híb. Sahel & IT & $4,15 \mathrm{abc}$ & $4,2 \mathrm{~cd}$ & $0,34 \mathrm{abc}$ & $12,2 \mathrm{ab}$ & $15,7 \mathrm{c}$ & $3.281,6 \mathrm{~cd}$ \\
Híb. THX-04 & IT & $4,17 \mathrm{abc}$ & $4,9 \mathrm{ab}$ & $0,36 \mathrm{abc}$ & $13,7 \mathrm{ab}$ & $24,0 \mathrm{ab}$ & $5.503,0 \mathrm{a}$ \\
Híb. THX-05 & IT & $4,23 \mathrm{a}$ & $4,9 \mathrm{ab}$ & $0,33 \mathrm{abc}$ & $15,5 \mathrm{a}$ & $20,9 \mathrm{abc}$ & $4.771,1 \mathrm{abc}$ \\
Híb. THX-06 & IT & $4,23 \mathrm{a}$ & $4,6 \mathrm{abc}$ & $0,29 \mathrm{bc}$ & $15,8 \mathrm{a}$ & $21,7 \mathrm{abc}$ & $3.583,0 \mathrm{bcd}$ \\
\hline CV (\%) & & 1,46 & 5,69 & 13,36 & 13,88 & 13,97 & 18,68 \\
\hline
\end{tabular}

*Híb.= híbrido; PA= polinização aberta; Médias na coluna seguidas de mesma letra, não diferem entre si, pelo teste de Tukey a 5\%. 
entre os frutos restantes nas plantas submetidas ao raleio. Resultados similares foram relatados por Melo et al. (2007) que avaliaram cruzamentos dialélicos entre genótipos de tomateiro de mesa e verificaram médias de LR entre 5,6 e $7,2 \mathrm{~cm}$.

Para os componentes de qualidade dos frutos de tomateiro, não houve efeito significativo da interação entre o manejo (raleio e não raleio de frutos) e cultivares e nem de manejo (Tabela 3). No entanto, houve diferenças significativas entre as cultivares evidenciando que os genótipos são geneticamente contrastantes e que, no presente estudo, tais características foram influenciadas unicamente pela constituição genotípica de cada cultivar. Esses resultados são concordantes com os descritos por Guimarães et al. (2004), que não encontraram diferenças significativas quanto a SS/AT, AT, SS e pH de tomateiros do grupo Santa Cruz submetidos à poda apical e de cachos florais.

Os valores de $\mathrm{pH}$ encontrados no presente estudo para as cultivares de tomate dos grupos Santa Cruz e Italiano (Tabela 4) variaram de 4,23 (THX-05 e THX-06) a 4,07 (THX-03) e foram similares aos relatados por Camargos et al. (2000) e Carvalho \& Tessarioli Neto (2005), corroborando a classificação dos frutos de tomate como ácidos, segundo Giordano et al. (2000). O genótipo experimental THX-03 obteve valor de pH inferior aos híbridos THX-05 $(4,23)$, THX-06 $(4,23)$ e Netuno $(4,21)$.

O teor de sólidos solúveis (SS), determinado $\mathrm{em}^{\circ}$ Brix é o principal componente responsável pelo sabor do fruto e, pode indicar a influência causada pela adubação, temperatura e irrigação, além de ser uma característica genética da cultivar (Giordano et al., 2000). No caso do uso de tomate como matéria-prima para processamento, a porcentagem de SS tem influência marcante sobre o rendimento industrial. Portanto, quanto maior o teor de sólidos solúveis, maior é o rendimento e menor o gasto de energia no processo de concentração da polpa. Nesse trabalho, observou-se, no grupo Santa Cruz (Tabela 4), valor médio de SS de 4,7\% para todas as cultivares avaliadas com amplitude de 5,0\% ('Avalon' e 'Débora Max') a 3,8\% (THX-03).
THX-03 diferiu dos genótipos comerciais utilizados como testemunhas e de dois outros híbridos experimentais (THX-01 e THX-02). É importante salientar que ‘Avalon' é um híbrido que tem como um de seus genitores um genótipo de porte determinado selecionado para processamento industrial (Melo et al., 2009). No que se refere ao grupo Italiano, 'THX-04' e 'THX-05', ambos com $4,9 \%$ de SS, mostraram-se superiores aos híbridos comerciais Sahel $(4,2 \%)$ e Giuliana (4,1\%). Essas diferenças se devem, provavelmente, à característica genética de cada cultivar. Resultados similares foram encontrados no experimento de 2007 realizado por Shirahige et al. (2009), utilizando os mesmos híbridos experimentais. Ferreira (2001) obteve valores entre $3,57 \%$ a $3,75 \%$ para frutos de 'Santa Clara' produzidos em campo. Já Carvalho \& Tessarioli Neto (2005) relataram valores de 4,49\% para 'Débora Max' e 5,05\% para 'Andréia', sendo essa última cultivar pertencente ao grupo Italiano ou Saladete.

A acidez titulável (AT), representada pelo teor de ácido cítrico, influencia principalmente o sabor dos frutos (Giordano et al., 2000). Os valores da acidez titulável variaram de 0,41\% (THX-02) a 0,34\% (THX-01) para genótipos do grupo Santa Cruz, e de 0,36\% (THX-04) a $0,28 \%$ ('Netuno') do segmento Italiano (Tabela 4). Valores similares de AT foram reportados por Gil et al. (2002) $(0,35 \%)$ e Carvalho \& Tessarioli Neto (2005) $(0,38 \%$ a $0,41 \%)$. O genótipo experimental THX-02 obteve valor de AT superior aos híbridos testemunhas Netuno $(0,28 \%)$ e Giuliana $(0,29 \%)$. Os demais híbridos experimentais não diferiram estatisticamente das testemunhas.

O sabor do tomate está relacionado com a presença de diversos constituintes químicos, destacando-se açúcares e ácidos, além de suas interações. Conhecendo-se o teor de sólidos solúveis e de acidez titulável dos frutos é possível estabelecer a relação SS/AT. Alto valor na relação indica uma excelente combinação de açúcar e ácido, a qual se correlaciona com sabor suave, enquanto que valores baixos estão diretamente relacionados com sabor ácido (Zambrano et al., 1996). Segundo Kader et al. (1978), frutos de alta qualidade contêm mais de $0,32 \%$ de AT, $3 \%$ de SS e relação SS/AT maior que 10 . Os genótipos avaliados exibiram valores para a relação $\mathrm{SS} / \mathrm{AT}$ acima de 10 , variando de 10,3 ('THX-03') a 15,8 ('THX-06'), sendo, portanto, adequados para o consumo in natura (Tabela 4).

$\mathrm{Na}$ Tabela 4, encontram-se os dados referentes aos teores de ácido ascórbico (AA). 'Avalon' destacou-se pelo maior teor de AA (25,0 mg $\left.100 \mathrm{~g}^{-1}\right)$, mas diferiu apenas de 'Sahel' (15,7 mg $\left.100 \mathrm{~g}^{-1}\right) \mathrm{e}$ 'Netuno' (17,7 mg $\left.100 \mathrm{~g}^{-1}\right)$. Os híbridos experimentais THX-01, THX-02, THX-03 e THX-04 obtiveram teores de vitamina $\mathrm{C}$ estatisticamente iguais à maioria das testemunhas comerciais, superando o híbrido Sahel. O valor médio de AA relativo aos genótipos do segmento Santa Cruz (23,1 mg 100 $\mathrm{g}^{-1}$ ) encontra-se de acordo com a média padrão para frutos de tomate, que é de $23 \mathrm{mg} 100 \mathrm{~g}^{-1}$, enquanto o valor médio de AA para as cultivares do segmento Italiano (19,9 mg $\left.100 \mathrm{~g}^{-1}\right)$ está abaixo da média padrão para frutos de tomate (Crawford, 1966).

Os teores de licopeno encontrados variaram de 2.194,5 $\mu \mathrm{g} 100 \mathrm{~g}^{-1}$ ('Giuliana') a 5.707,7 $\mu \mathrm{g} 100 \mathrm{~g}^{-1}$ ('Débora Max'). Os híbridos Débora Max, THX01, THX-02 e THX-04 foram iguais quanto ao teor de licopeno e superaram 'Giuliana', 'Sahel', THX-03 e THX-06. Os valores médios para o teor de licopeno das cultivares dos segmentos Santa Cruz e Italiano foram 4.976,9 $\mu \mathrm{g} 100 \mathrm{~g}^{-1}$ e $3.897,0 \mu \mathrm{g} 100 \mathrm{~g}^{-1}$, respectivamente. Esses valores são inferiores à faixa de teor ideal desse pigmento (5.000 a $8.000 \mu \mathrm{g} 100 \mathrm{~g}^{-1}$ ), o qual confere a cor vermelha ao fruto de tomate (Campos, 2006). Portanto, em geral, os frutos das cultivares avaliadas no presente estudo, independentemente do tipo varietal, apresentaram deficiência de cor. Com relação ao segmento Santa Cruz, os teores de licopeno verificados nesse trabalho, em média, estão abaixo daqueles que Campos (2006) reportou para cultivares do mesmo grupo $(5.123,0 \mu \mathrm{g} 100$ $\mathrm{g}^{-1}$ ). Deve ser destacado que, os baixos teores de licopeno, em média, para os híbridos do tipo Italiano, provavelmente está diretamente relacionado ao fato de que três deles são do tipo longa vida 
('Giuliana', 'Netuno' e THX-06) sendo portadores de genes que retardam o processo de amadurecimento do fruto e, em consequência, proporcionam o aumento de sua preservação pós-colheita. Todavia, tais genes, desvantajosamente, contribuem para redução do teor de licopeno, afetando significativamente a cor e a qualidade gustativa dos frutos (Boiteux et al., 2008). Giordano et al. (2000) ressaltam que em tomate, a cor do fruto é um importante parâmetro de qualidade, quer para consumo in natu$r a$, quer para processamento industrial. Deve ser enfatizado que hortaliças e frutas naturalmente com altos teores de vitamina $\mathrm{C}$ e de licopeno revestem-se, na atualidade, de grande importância devido às propriedades antioxidantes desses fitonutrientes, que contribuem para redução do risco de doenças cardiovasculares e de algumas formas de câncer (Boiteux et al., 2008).

De acordo com os resultados obtidos no presente trabalho, o raleio dos frutos proporcionou incremento da produtividade comercial, massa média, comprimento e largura do fruto para os híbridos THX-02, THX-03, THX-04, THX-05 e 'Netuno', e não mostrou vantagens para produção e seus componentes para os demais genótipos e características avaliadas. Considerando o raleio de fruto, os genótipos Giuliana e Sahel obtiveram maior produtividade comercial e massa média do fruto. Dentro das plantas sem o raleio de fruto, 'Netuno' alcançou maior número de frutos por planta, porém, o híbrido Sahel foi quem se destacou por apresentar alto potencial produtivo e tem a tendência de exibir elevado pegamento de frutos por racemo. O raleio não influenciou a qualidade organoléptica dos genótipos avaliados. As diferenças dos componentes de qualidade dos frutos entre as cultivares se devem à constituição genotípica de cada cultivar.

\section{AGRADECIMENTOS}

Às instituições que apoiaram este projeto de pesquisa: FAPESP (processo: 2007/55896-8), CAPES, IAC e à HORTIVALE Ltda.

\section{REFERÊNCIAS}

ALVARENGA MAR. 2004. Tomate: produção em campo, em casa-de-vegetação e em hidroponia. Lavras: Ed. UFLA, 400p.

BOITEUX LS; MELO PCT; VILELA JV. 2008. Tomate para Consumo in natura. In: ALBUQUERQUE ACS; SILVA AG (eds). Agricultura Tropical: Quatro Décadas de Inovações Tecnológicas, Institucionais e Políticas. Brasília/DF: Embrapa Informação Tecnológica, 1:557-567.

CALIMAN FRB. 2003. Produção e qualidade de frutos de genótipos de tomateiro em ambiente protegido e no campo. Viçosa (MG): Universidade Federal de Viçosa (Tese mestrado).

CAMARGOS MI; FONTES PCR; FINGER FL; CARNICELLI JHA. 2000. Qualidade de tomate longa vida em estufa, influenciada por espaçamento e número de cachos por planta. Horticultura Brasileira 18: 562-563.

CAMPOS FM. 2006. Avaliação de práticas de manipulação de hortaliças visando a preservação de vitamina $C$ e carotenóides. Viçosa (MG): Universidade Federal de Viçosa (Tese mestrado).

CARVALHO CRL; MANTOVANI DMB; CARVALHO PRN; MORAES RMM. 1990. Análises químicas de alimentos. Campinas: ITAL, 121p. (Manual Técnico).

CARVALHO LA; TESSARIOLI NETO J. 2005. Produtividade de tomate em ambiente protegido, em função do espaçamento e número de ramos por planta. Horticultura Brasileira 23: 986-989.

CHITARRA MIF; CHITARRA AB. 1990. Póscolheita de frutos e hortaliças, fisiologia e manuseio. Lavras: ESAL/FACEPE, 320p.

CRAWFORD AMc.1966. Alimentos: seleção e preparo. Rio de Janeiro: Record, 387p.

DORAIS M; GOSSELIN A; PAPADOPOULOS AP. 2001. Greenhouse tomato fruit quality. Horticultural Reviews 26: 239-306.

FERREIRA MMM. 2001. Índice de nitrogênio para o diagnóstico do estado nutricional do tomateiro em presença e ausência de adubação orgânica. Viçosa: Universidade Federal de Viçosa. 145p (Tese doutorado).

FNP CONSULTORIA E COMÉRCIO. AGRIANUAL 2009: Anuário da agricultura brasileira. São Paulo, 2009. 520 p.

GIL MI; CONESA MA; ARTÉS F. 2002. Quality changes in fresh cut tomato as affected by modified atmosphere packaging. Postharvest Biology and Technology 25: 199-207.

GIORDANO LB; SILVA JBC; BARBOSA V. 2000. Escolha de cultivares e plantio. In: SILVA JBC; GIORDANO LB. Tomate para processamento industrial. Brasília/DF: Embrapa Informação Tecnológica, p.36-59.

GUIMARÃES MA; CALIMAN FRB; SILVA DJH; MATTEDI AP; MARIN BG. 2004. Produção e sabor de tomate em função da desponta e desbaste de cachos em tomateiro do grupo Santa Cruz. In: CONGRESSO BRASILEIRO DE OLERICULTURA, 44. Anais... Brasília: SOB. Horticultura Brasileira 22.

KADER AA; MORRIS LL; STEVENS MA; ALBRIGHTHOLTON M. 1978. Composition and flavour quality of fresh market tomatoes as influenced by some postharvest handling procedures. Journal of American Society for Horticultural Science 113: 742-745.

LEALMAA;ARAÚJO ML; FERNANDES MCA. 2003. Raleio e capação na produtividade e na qualidade dos frutos de tomateiro cultivado em ambiente protegido, em sistema orgânico. Horticultura Brasileira 21: 267-267.

MACHADO AQ; ALVARENGA MAR; FLORENTINO CET. 2007. Produção de tomate italiano (saladete) sob diferentes densidades de plantio e sistemas de poda visando ao consumo in natura. Horticultura Brasileira 25: 149-153.

MELO PCT. 2003. Desenvolvimento sustentável da cadeia produtiva do tomate para consumo in natura no Brasil e os desafios do melhoramento genético. Horticultura Brasileira 21(2). Suplemento. CD-ROM.

MELO AMT; SOUZA LM; MELO PCT. 2007. Heterose para caracteres de produção e qualidade de frutos de tomate para consumo in natura. In: CONGRESSO BRASILEIRO DE OLERICULTURA, 47. Anais... Brasília: SOB. Horticultura Brasileira 25. Suplemento CD-ROM

MELO PCT; MELO AMT; BOITEUX LS. 2009. Overview and perspectives of tomato breeding for fresh market adapted to mild tropical climates of Brazil. Acta Horticulturae 821: 52-62.

NAGAI H. Avanços obtidos com o melhoramento genético do tomate no Brasil. 1990. In: Encontro nacional de produção e abastecimento de tomate, Viçosa. Anais... Viçosa: UFV: SOB: EPAMIG: EMATER-MG: CEASA-MG, p.88-107.

PELUZIO JM; CASALI VWD; LOPES NF; MIRANDA GV; SANTOS GR. 1999. Comportamento da fonte e do dreno em tomateiro após a poda apical acima do quarto cacho. Ciência Agrotécnica 23: 510-514.

RODRIGUEZ-AMAYA D. 2001. A Guide to Carotenoids Analysis in Food. Washington: International Life Sciences Institute Press, 64p.

SHIRAHIGE FH; MELO PCT; MELO AMT; JACOMINO AP; PURQUERIO LFV; ROQUEJANI MS. 2009. Yield and qualitative characterization of fresh market tomato hybrids of Italian and Santa Cruz Types. Acta Horticulturae 821: 81-88.

TANAKA A; FUJITA K. 1974. Nutriophysiological studies on the tomato plant. IV. Source-sink relationship and structure of the source-sink unit. Soil Science Plant Nutritional 20: 305-315.

TRANI PE; RAIJ B. 1996. Hortaliças. In: RAIJ B; CANTARELLAH; QUAGGIO JA; FURLANI AMC. Recomendações de adubação e calagem para o estado de São Paulo. Campinas: IAC, p.157-186. (Boletim Técnico 100).

WAMSER AF; MUELLER S; SANTOS JP; BECKER WF. 2007. Produção de tomate em função do espaçamento entre plantas e do número de cachos por haste no tutoramento vertical com fitilho. In: CONGRESSO BRASILEIRO DE OLERICULTURA, 47. Anais... Brasília: SOB. Horticultura Brasileira 25. Suplemento.

ZAMBRANO J; MOYEJA J; PACHECO L. 1996. Efecto del estado de madurez en la composición y calidad de frutos de tomate. Agronomia Tropical 46: 61-72. 